\title{
EL FORO VIRTUAL EN LA EDUCACION EN VALORES DE IGUALDAD
}

\section{THE VIRTUAL FORUM ON EDUCATION IN EQUALITY VALUES}

\author{
Miguel-Ángel Ballesteros-Moscosio \\ Universidad de Sevilla \\ miguelanba@us.es
}

Resumen: Andalucía en e-Igualdad fue uno de los proyectos incluidos dentro de la Iniciativa Comunitaria EQUAL. Este tipo de proyectos pretendió a través de la creación de redes profesionales la planificación, desarrollo y evaluación de proyectos que promovieran la innovación social, ya sea en sus contenidos o en sus procesos. El trabajo en red, la visión transnacional de Europa, y la promoción del uso de las TIC fueron ejes fundamentales en torno a los que se desarrollaron las diversas acciones encaminadas a la promoción de una cultura común donde la Igualdad fue el modus operandi del proyecto. En este trabajo, se presenta el desarrollo y aplicación de una metodología de análisis de contenido de los mensajes vertidos en los debates online desarrollados en los foros de la web del proyecto. El análisis descriptivo y cualitativo del contenido, se realiza desde un enfoque interpretativo, partiendo de posicionamientos propios del interaccionismo simbólico y la fenomenología. Viene a demostrar, a través de la experiencia práctica del proyecto Andalucía en eIgualdad, la oportunidad que supone el uso los foros como recurso óptimo para la educación en valores. Testa también variables sobre la interiorización de valores y significados, elementos facilitares de la construcción de la cultura y una visión crítica en el análisis de la desigualdad.

Palabras clave: Análisis de la comunicación online, foros de aprendizaje virtuales, innovación social, cultura, igualdad de oportunidades, género, TIC, aprendizaje adulto.
Abstract: Andalusia in e-Equality was one of the projects included within the EQUAL Community Initiative. These projects, through networking of professionals who plan, develop, and evaluate them, sought to promote social innovation, either in the projects' content or in their processes. Networking, a transnational vision of Europe, and promotion of the use of Information and Communications Technology (ICT) were key points around which actions were developed to promote a common culture where equality was the modus operandi of the project. In this paper, we present the development and implementation of a methodology for analysing the content of messages in online discussions that developed in the forums included in the website of the project. The descriptive and qualitative content analysis is performed using an interpretive approach based on a framework of symbolic interactionism and phenomenology. It shows, through practical experience of the Andalucía e-Equal project, the opportunity of using forums as optimal resources for values education. Also tested were variables on the internalization of values and meanings, facilitators for building a culture and a critical view in the analysis of inequality.

Keywords: Content analysis of online communication, learning forums for virtual learning, social innovation, culture, equal opportunities, gender, ICT, adult learning. 


\section{Introducción: los foros en la generación de conocimiento y concienciación crítica}

La preocupación de la Unión Europea por un desarrollo social armónico de su ciudadanía se ha puesto de manifiesto en la promoción de políticas encaminadas a mejorar las condiciones de las regiones más desfavorecidas de su territorio. El caso de Andalucía, región con altos índices de desempleo y en la que aún conviven elementos distorsionadores de la empleabilidad tales como la falta formación -especialmente en el ámbito tecnológico- o las situaciones de desigualdad, entre otras razones, por cuestiones de género, hicieron de nuestra comunidad autónoma un espacio de intervención prioritario, siendo considerada una de las regiones europeas Objetivo I.

La Iniciativa Comunitaria ${ }^{1}$ EQUAL ejemplifica, como pocas, este tipo de políticas públicas. Dirigida a la promoción de nuevas prácticas de lucha contra todo tipo de discriminación y de desigualdad en el mercado de trabajo, en un contexto de cooperación nacional y transnacional, buscó facilitar la inserción social y profesional de diversos colectivos susceptibles de padecer situaciones de desigualdad. IC EQUAL se sustentó en cuatro pilares fundamentales: capacidad de inserción profesional, espíritu de empresa, adaptabilidad e igualdad de oportunidades. En todas ellas estuvo presente el elemento tecnológico como escenario en el que se desarrolla la Sociedad del Conocimiento. Asimismo, supuso una oportunidad para que entidades de muy diversa naturaleza pudieran desarrollar redes profesionales de trabajo, denominados en este contexto de intervención Agrupaciones de Desarrollo², organizaciones reticulares que actuaron no sólo dentro de cada país, también generaron redes de carácter transnacional.

Andalucía en e-Igualdad fue uno de estos proyectos incluidos en la primera edición de la IC EQUAL en España y en el que la Universidad de Sevilla jugó un papel esencial. A su vez, formó parte de la red transnacional Europe in e-Quality junto con al Proyecto italiano Pórtico, liderado por la Universidad de Bolonia, y el Proyecto austriaco Noel, cuyo principal agente dinamizador fue el gobierno de Baja Austria. Andalucía en e-Igualdad centró sus acciones en el desarrollo del eje temático Igualdad de Oportunidades, concretamente dentro del área "Reducir desequilibrios entre hombres y mujeres y apoyar la eliminación de la segregación en el trabajo" utilizando para ello la información, la formación y la generación de conocimiento a través de la investigación para promover una cultura de igualdad. Para ello, uno de los aspectos trabajados en este proyecto fue el análisis de la cultura y el desarrollo de modelos de rol femeninos en distintos ámbitos (jurisprudencia, empresa, en la historia, etc.) junto a la génesis de procesos de reflexión sobre la situación de la mujer.

Asimismo, el componente tecnológico estuvo presente tanto en la gestión del proyecto como en las distintas actividades que desarrolló de investigación, de formación, de difusión de resultados y de sensibilización sobre la cuestión de género. Los foros de comunicación online destacados en la web del proyecto fueron utilizados como estrategia promotora de la reflexión y el análisis por parte de los participantes sobre la desigualdad ligada a la cuestión de género. En este sentido, se usó la comunicación asincrónica para, por un lado, expresar experiencias vividas y contrastarlas con las vivencias de otros, buscando el conflicto cognitivo, que haga surgir nuevo conocimiento e ideas divergentes a las consideradas propias del discurso normalizado de

\footnotetext{
1 En adelante IC.

2 En adelante AD.
} 
nuestra sociedad, y, por otro, para facilitar el desarrollo de una conciencia crítica ante la desigualdad por razón de género.

\subsection{Rol de los artefactos tecnológicos en la dinamización del cambio social y de la participación}

Las Tecnologías de la Información y la Comunicación ${ }^{3}$ pueden aportan un valor añadido a los procesos de interacción (Crook, 2001, Cook-Shather, 2000; De Pablos, 2001) por cuanto que diversifica los espacios y tiempos destinados a la comunicación. Un ejemplo claro de ello lo tenemos en herramientas tales como las redes sociales o las herramientas de mensajería instantánea que nos permiten estar en permanente conexión con otros. Asimismo, son herramientas que pueden servir para mejorar los procesos formativos y de reflexión (Sevillano, 2008, 2009; Mas et al., 2006; Ortega y Chacón, 1999, 2007; De Pablos, 2006, 2009; Inoue, 2008), aportar nuevas posibilidades de reciclaje profesional y personal (De Pablos, 2004, 2005, 2009) y ayudar a los procesos de transferencia de conocimiento (Sevillano, 2009). El escenario de globalización tecnológica al que asistimos abre también muchas y nuevas posibilidades para el desarrollo de la igualdad de oportunidades: acceso a gran diversidad de información, nuevas formas de trabajo como el teletrabajo, oportunidades de formación no presencial, etc. Pero, al mismo tiempo, posibilita nuevos espacios para la desigualdad: acceso desigual a los recursos tecnológicos y, por ende, a las oportunidades que ofrece el ciberespacio, perpetuación de estereotipos trasladándolos del ámbito no virtual al virtual, etc.

Las TIC no dejan de ser un medio a través del cual las personas interactúan entre sí y con el medio, constituyéndose así en instrumentos mediadores de las prácticas sociales. Ejemplos de ello los encontramos en la creación de universos paralelos tales como la realidad virtual o la realidad aumentada, o en el uso de los blogs, aplicaciones de mensajería instantánea, los foros o chats como medios de relación entre las personas. Esta potencialidad para facilitar la interacción entre sus usuarios es uno de sus puntos fuertes, quizás el logro más notable sea la globalización del hecho comunicativo (Cebrián, 1998). Al mismo tiempo, el aprovechamiento de su potencial real está condicionado, como señala Sánchez (2001): "las TIC no dejarán más que ser fuegos de artificio, si no contribuyen a una sociedad más equitativa, más igualitaria, donde su potencial se haga accesible a todos, y contribuya a la mejora de los niveles y calidad de vida de los ciudadanos", esto es, han de servir para generar nuevas prácticas culturales y formas de actuación orientadas al desarrollo social armónico de la ciudadanía. Por mucha información de la que dispongamos en nuestro entorno, ésta no tiene porqué mejorar nuestra capacidad de aprender, de conocer o de saber (Gisbert, 2000), en ocasiones puede ser hasta contraproducente la sobreabundancia informativa. Un ejemplo de ello estaría en la apabullante diversidad de contenidos y recursos existentes en la red, que como nos recuerda Sierra (2000), "no exige ser asimilada, ni siquiera recibida por todos los usuarios".

Si bien el mundo y el conocimiento son construidos socialmente (Reyes y Toledo, 2008), "este nuevo espacio social requiere constructores, actores, y no sólo navegantes, observadores o lectores que consumen lo que otros producen", como escribe Chan (2005). Es necesaria la promoción de una ciudadanía activa y participativa que use esos nuevos recursos con una visión transformadora, más que como meros consumidores. Para ello es necesario en la Sociedad del Conocimiento, por una parte "diseñar nuevos entornos de comunicación auditiva, visual y escrita, donde el usuario deje de ser un mero receptor y pase a ser un actor activo dentro de las

3 En adelante TIC. 
mismas" (Fonseca, 2009), y, en segundo lugar, desarrollar un conocimiento óptimo de los recursos TIC y sus potencialidades (Sevillano, 2007; Varis, 2003; De Pablos, 2004). Los procesos de sensibilización en la red pueden entenderse también desde esta doble perspectiva: bien como consumidor de los contenidos online o como participante en la generación de dichos contenidos. En este sentido, es una oportunidad para los agentes educativos y los investigadores sociales usar la retícula de relaciones que está generando la tecnología digital a través de la cual reconstruimos la realidad sociocultural en la que nos insertamos (Ortega, 2004) para generar procesos de reflexión a partir de los cuales se propicien los cambios necesarios hacia una cultura que integre la totalidad del capital humano de nuestra sociedad en igualdad de condiciones.

\subsection{Comunicación online: Una oportunidad para el desarrollo de la interacción educativa y la generación de valores}

La Declaración de la Cumbre Mundial sobre Sociedad de la Información (2004: 3), en su artículo 4, considera la comunicación como "un proceso social fundamental, una necesidad humana básica y el fundamento de toda organización social". El acto comunicativo supone necesariamente una reciprocidad, bidireccionalidad; supone interacción e interdependencia (Sierra, 2000; García-Madrigal y Visen, 1994), en la que no sólo existe información cognitiva, también afectiva (Aguirre, 2004), y es mediatizada por las interpretaciones personales de la realidad, de manera que lo que decimos es siempre escuchado bajo el filtro de las percepciones, experiencias y convicciones del que escucha (Espinosa, 2011: 112). Comunicarse significa un proceso de encuentro, de escucha, en el que los participantes aceptan los argumentos de otros y son capaces de replantearse o modificar las propias ideas. Comunicarse, en estos términos, supone dejar la zona de confort y estar abierto a nuevas ideas, a veces contrarias a nuestra línea de pensamiento, supone aprender con otros y de otros, cuya base está en la interacción (Tirado, Boza y Guzmán, 2008; Allwright, 1984). El proceso comunicativo lo entendemos como algo profundo, como un proceso de construcción cultural, en el que las personas comparten y se sienten comunidad (Tesouro y Puiggalí, 2006; Sierra, 2000; Gisbert, 2000). Un proceso en el que "construimos la realidad a través de lo observado y aprendido; a través de explicaciones (normas, principios, creencias, teorías, es decir, modelos mentales compartidos). Construimos el mundo en que vivimos a través de nuestras interpretaciones de él" (Espinosa, 2011: 112). Reinterpretamos nuestro conocimiento y la realidad basándonos en experiencias compartidas. Es precisamente en la elaboración del mensaje donde la información se juega su objetividad (Sierra, 2000: 465). Como plantea Gómez (2001: 134) el lenguaje es el principal simbolizador social el cual, "materializado en discurso, se constituye en instrumento y evidencia de las luchas simbólicas de una sociedad". Es a través del discurso donde se construye la comunidad, posibilitando el cambio de las ideas y las prácticas (Mingorance y Estebaranz, 2009: 106), siendo el discurso compartido una de las características del conocimiento educativo (De la Mata et al., 2009).

Los nuevos recursos TIC para la comunicación han puesto en las manos de los educadores e investigadores sociales nuevos espacios de comunicación en los que es pertinente el análisis crítico del discurso, tanto más cuando estos son empleados como estrategia facilitadora del aprendizaje y la promoción de cultura y valores entre los participantes en el discurso. Sirven como medio para revisar los procesos históricos que son la base de cómo se han construido los significados y las implicaciones políticas y culturales, actuales y futuras (Youngs, 2001). Como nos recuerda De Pablos (2001: 172), "los lenguajes sociales y géneros discursivos son elaboraciones 
culturales", motivo por el que el discurso puede ser empleado para clarificar valores y experiencias, contrastarlas con otros y generar aprendizaje en colaboración con otros. Esto significa que no es sólo aquello que se comunica lo que puede ser estudiado, también puede serlo cómo se interpreta aquello que se dice o, yendo más allá, qué nos hace ver la realidad tal y como la interpretamos. En consecuencia, la innovación social y el cambio se sitúan en el seno de los procesos de comunicación ya que en ellos las personas establecen contactos, intercambios y propuestas (Estebaranz, 2005: 9). Es el discurso que se establece en situaciones de diálogo social el elemento que posibilita la generación de conocimiento y cultura (De la Mata et al., 2009). El análisis de cómo se usan los recursos comunicativos basados en la escritura, tales como el correo, los foros, los blogs, los chats o las redes sociales, es muy conveniente para conocer, desde una perspectiva cultural, cómo se gestan y comparten los significados dentro de un colectivo.

\subsection{Los foros online como recurso para la construcción de conocimiento}

Martín (2007) define los foros como espacios de comunicación asíncrona y en grupo, cuya naturaleza es la de promover el encuentro y la comunicación entre personas interesadas por compartir y cambiar impresiones con otras personas de intereses similares, y que tienen su mejor expresión dentro de los cursos impartidos a través de teleformación. Ornelas (2007: 4), por su parte, los define como "centros de discusión acerca de un tema en particular, que concentra opiniones de muchas personas de distintos lugares, en forma asincrónica. Esto último significa que la comunicación entre las personas se da sin necesidad de que éstas se encuentren usando la plataforma de manera simultánea. Cada persona que se conecte, independientemente del momento, tendrá acceso a los mensajes que queden registrados en la temática objeto de la discusión". En definitiva, son un recurso que favorece el aprendizaje colaborativo y la construcción del conocimiento, ya que permite la interacción y el intercambio entre sus usuarios (Brito, 2004). Los responsables de la emisión de mensajes son los propios participantes. El hecho de dejar constancia por escrito de las ideas, principios y valores que orientan las acciones, de los conocimientos y necesidades, de los avances y fracasos, de los aprendizajes y obstáculos encontrados, en un proceso en red no es una cuestión baladí. Significa aprovechar la experiencia, dar oportunidad a la reflexión personal y colectiva para mejorar dichos procesos, al tiempo que un medio adecuado para la gestión y la transferencia del conocimiento entre los participantes. La discusión online se constituye en "una estrategia fundamental en una democracia. Es la oportunidad de expresar puntos de vista diferentes..." (Estebaranz, 2007: 158), por cuanto que permite poner de manifiesto los valores internos de los que participan en ella, pero para ello hay que crear las condiciones pedagógicas y sociales para que dicho proceso de construcción se lleve a cabo de forma óptima (Hoyos y Martínez, 2004). Las herramientas TIC que facilitan la comunicación online son recursos adecuados para el aprendizaje en equipo a través del diálogo, facilitando el intercambio transparente de experiencias, la capacidad de negociar de forma eficaz los modelos mentales de cada uno y el trabajo en la modificación y mejora de los marcos conceptuales de todos los participantes en el discurso.

Hara, Bonk y Angeli (2000) sugieren que la comunicación asincrónica apoya los principios del aprendizaje constructivista porque permite que los alumnos articulen, lean y reflexionen fácilmente sobre los conceptos. En el mismo sentido se pronuncia Lara (2005) cuando se refiere al uso de los blog en la Enseñanza Superior. Además, el hecho de tener que escribir aquello que se dice en un medio virtual asincrónico como es el foro, el correo, un blog o una wiki, obliga a los participantes a ser más reflexivos que en una comunicación cara a cara o en otros recursos TIC sincrónicos, como por 
ejemplo un chat (Hawkes, 2006; Conrad y Donaldson, 2004), herramientas mucho más marcadas por la inmediatez. Asimismo, este tipo de espacios para comunicación asincrónica permiten que todas las voces sean escuchadas, ya sea en el pequeño o en el gran grupo, ayudando así a los participantes a sentirse parte de la comunidad de aprendizaje e incrementando su motivación para interactuar con sus compañeros (Conrad y Donaldson, 2004).

Urra (2007) diferencia los foros de otros recursos para la comunicación online disponibles hoy día, tales como los weblogs, blogs o bitácoras. Mientras que estos últimos se crearon pensando en facilitar la comunicación con audiencias amplias, los foros se crearon para permitir la discusión ordenada de temas con el objetivo de buscar soluciones y tratar de llegar a una respuesta que resuelva un problema o situación. Por este motivo este recurso puede ser adecuado para el desarrollo de la reflexión conjunta y la sensibilización en cuestiones relacionadas con los valores y experiencias de los participantes.

En su éxito y evolución es fundamental el interés que provoquen, la utilidad que aporten y la moderación y mantenimiento que se haga sobre el mismo para asegurar su permanencia. De este modo, en el caso del foro o de las listas de distribución es crucial la percepción de utilidad de los contenidos disponibles en la herramienta, incluso permitiendo que su uso se mantenga incluso una ve vez finalizada la actividad formativa o conseguido el objetivo para el cual se diseñó (Michaelson y Pohl, 2001). También juega un papel esencial el responsable de su gestión, por cuanto que su responsabilidad radica en el cumplimiento de la misión para la que se creó el foro o la lista. Sea como fuere, los foros y listas de distribución presentan sus propios ciclos vitales, relacionados con la evolución en la frecuencia de emisión de mensajes y calidad de los mismos, tal y como señala Kat Nagel (1994).

La evolución ideal de los foros o listas de distribución se dirige a la formación de "una comunidad virtual automoderada donde un sector activo se implica en su dinámica y funcionamiento" (Feliu, 1999), es lo que se denomina como "masa crítica", es decir, una minoría activa que dinamice y corrija su decadencia, un conjunto de participantes comprometidos con la tarea de comunicarse.

Páez (2008) considera que el foro de discusión es un instrumento eficaz en la formación del pensamiento crítico de los participantes, tanto más en situaciones formativas de Educación Superior y postgrado. Analiza un foro de aprendizaje online implantado en la plataforma gratuita icenet.org. En este foro participaron 23 profesionales en un curso de Maestría en Desarrollo Curricular. Tras analizar el contenido de los mensajes enviados al foro distingue tres formas de diálogo entre sus participantes: social o charla informal que aporta sentimiento de pertenencia al grupo online; el diálogo argumentativo, que es razonado y acerca las posiciones de los participantes, y el diálogo pragmático que es también razonado pero que trata de informar, indagar, potenciar el intercambio de ideas en relación con el tema que se trabaje. Páez (2008) considera, asimismo, el uso de esta herramienta como un recurso útil para que los participantes aporten contenidos enriquecedores y de valor a partir del análisis y la evaluación crítica de los temas a tratar en el discurso, indaguen respecto al mismo, pregunten y reflexionen conjuntamente.

Jeong (2003) analiza también varios debates online con el objeto de estudiar la interacción de un grupo y el desarrollo del pensamiento crítico. Para ello empleó un sistema de análisis con doce categorías. Entre sus conclusiones están, en primer lugar, a nivel metodológico, la validez de instrumentos de análisis de este tipo; en segundo lugar, elaboró diversos patrones de interacción, concluyendo que aquellos 
debates en los que concurrían posiciones encontradas fueron los que promovieron una mayor discusión y pensamiento crítico. Por último, concluye que la evaluación de los argumentos era más probable encontrarla en el momento de la elaboración de conclusiones más que cuando los argumentos eran presentados. En consecuencia, es necesario promover puntos de vista opuestos en el debate, con el objeto de enriquecerlo, tratando de evitar los procesos de acomodación descritos por Wallace (2001). El pensamiento crítico se refuerza y aparece al mezclar las diferentes experiencias de los participantes en los debates virtuales. En este sentido el diseño de la actividad sobre la que se discute y la evaluación de los contenidos tratados son igualmente importantes a la hora de valorar sus resultados (Buraphadeja y Dawson, 2008).

\section{Caso de estudio, objetivos y metodología: el Proyecto Andalucía en e-Igualdad}

Andalucía en e-Igualdad, constituyó la Agrupación de Desarrollo (AD) número 428 dentro de los proyectos españoles incluidos en la Iniciativa Comunitaria EQUAL. En ella se integraron diez entidades, públicas y privadas, de muy diversa tipología y tamaño. Éstas fueron: el Servicio Andaluz de Empleo de la Junta de Andalucía, la Fundación Directa, la Universidad de Sevilla, las Asociaciones de Empresarias de Cádiz y Sevilla, la Asociación Liderared, la Diputación de Córdoba, la Sociedad Pública Sevilla Siglo XXI dependiente de Diputación de Sevilla, el Colegio de Psicólogos y la Revista digital Cibersur. Cada una de estas organizaciones aportaba, en la medida de sus posibilidades, recursos, ya fueran materiales o humanos. El equipo humano que formaba parte de esta red de trabajo tenía una naturaleza interdisciplinar, en la que el $80 \%$ fueron mujeres.

Esta AD tenía un carácter geográfico, desarrollando sus actuaciones en Andalucía, pero centrándose en las provincias de Cádiz, Córdoba y Sevilla. A través de este proyecto, con palabras de la misma web del proyecto (www.e-igualdad.org) se "pretende reformular la Sociedad de la Información 'en femenino', potenciar el desarrollo de la carrera profesional y la presencia de las mujeres, favorecer la creación de redes de mujeres". Para ello es necesario propiciar su presencia en la red y una de las estrategias más adecuadas es a través de la generación de contenidos online en los que se promueva una visión crítica de su papel en el mundo actual.

En este sentido, la nueva cultura digital se caracteriza por una transformación de los procesos de comunicación y de gestión del conocimiento, donde la organización en red y el trabajo colectivo se hacen imprescindibles, ya que es necesario crear espacios en los que se dé oportunidad a la transferencia del conocimiento. Estos espacios han de ser gestionados también desde una visión de género, propiciando la formación de comunidades profesionales que compartan conocimiento y experiencia. El gran reto de este proyecto fue ayudar a construir la igualdad de oportunidades entre los sexos, sin ignorar las diferencias entre hombres y mujeres, convirtiendo a las mujeres en protagonistas activas del cambio, tanto en su impacto como en su gestión. Esto supuso asumir una serie de tareas y actividades dirigidas a la producción cultural de contenidos con visión de género.

La comunicación virtual desarrollada en el marco del proyecto Andalucía en e-Igualdad ha tenido su escenario en el portal www.e-igualdad.org, un espacio en Internet punto de encuentro para las usuarias del proyecto tanto nacional como transnacional, pero también donde cualquier internauta pudo acceder a contenidos y herramientas telemáticas destinadas a la formación, el asesoramiento y el acompañamiento. Los 
contenidos del portal estuvieron dirigidos a mejorar el posicionamiento de las mujeres en los nuevos entornos y valores profesionales de la sociedad del conocimiento, ofreciendo online una gran diversidad de itinerarios formativos, dinamizados por tutores y expertos. Además incluyó diversos foros temáticos repartidos por las distintas áreas del portal, además de otros recursos destinados a la comunicación. Dichos foros fueron ideados para suscitar el debate online sobre cuestiones dilemáticas que afectan al desarrollo en igualdad de oportunidades de las mujeres en la sociedad actual.

Con nuestro trabajo pretendemos analizar la comunicación online mantenida en el portal www.e-lgualdad.org como instrumento para la generación de opinión y reflexión en torno a la cuestión de la igualdad de oportunidades. Supuso una forma de participación activa de los usuarios y usuarias del portal para visibilizar experiencias relativas al proyecto, en cualquiera de sus facetas, así como para visibilizar experiencias vividas en primera persona. En este trabajo se analizan los distintos foros no sólo en términos de estructura o funciones del discurso sino también, y lo que nos parece más importante, en su contenido por cuanto que ayudan a facilitar la construcción de cultura y una visión crítica en el análisis de la desigualdad.

Nuestro enfoque de investigación fue fundamentalmente interpretativo. Desde este punto de vista, el investigador participa activamente al ser miembro del equipo de evaluación interna del proyecto Andalucía en e-Igualdad. Se pretende comprender la situación de aprendizaje a través de sus participantes, es decir, cómo viven la desigualdad aquéllos que participan en el proceso. Buscamos no sólo, conocer los hechos, sino también las interpretaciones que hacen las personas implicadas en estos hechos, siguiendo también una visión fenomenológica del hecho estudiado, poniendo especial énfasis en los procesos de interacción entre los participantes en los debates online analizando las percepciones y reflexiones de los durante la gestión de los productos y tareas transnacionales.

Partimos de la descripción inicial de la realidad objeto de estudio para posteriormente comprender qué ocurre en esa realidad e interpretarla, buscando desvelar las relaciones entre las creencias, las prácticas y las concepciones de los participantes en los foros de aprendizaje destacados en el portal del proyecto. Nos situamos en nuestro proceso investigador desde una perspectiva fenomenológica, analizando las percepciones y reflexiones de los usuarios y usuarias de los foros del proyecto, que participaron espontáneamente en los debates online sincrónicos y asincrónicos, así como desde el interaccionismo simbólico, al observar los procesos de interacción entre los participantes en los debates online.

El nuestro es, además, un diseño de investigación híbrido o mixto, que combina las metodologías de investigación cuantitativas y cualitativas, desde una visión comprensiva del proceso investigador, ya que los resultados obtenidos de este modo pueden enriquecer y mejorar nuestra comprensión de las cuestiones estudiadas (Molina et al., 2012: 30). La metodología cuantitativa se ha aplicado en el procesamiento y análisis de los datos obtenidos susceptibles de codificación numérica, por frecuencias o porcentajes, base del posterior estudio descriptivo. Se recopilaron todos y cada uno de los mensajes enviados a cada uno de los foros temáticos activos incluidos en la web del proyecto $(\mathrm{N}=8)$. Posteriormente se realizó un estudio descriptivo de las frecuencias y porcentajes de uso de cada uno de los códigos en los que se clasificaron los contenidos comunicativos vertidos en los distintos foros. Se cuantificaron, por un lado, el número de mensajes o intervenciones recogidas en los diferentes foros del portal, así como su evolución a lo largo del tiempo, su destinatario, diferenciando el elemento "género" y, por otro lado, los resultados de la codificación cualitativa 
proveniente del análisis de contenido de los mensajes emitidos en los distintos foros incluidos en la web del proyecto (www.eigualdad.org). Respecto al enfoque cualitativo, se llevó a cabo realizando el análisis de contenido de los distintos mensajes recopilados, atendiendo a un sistema de categorías múltiple, justificado y probado con anterioridad (Estebaranz, Mingorance y Ballesteros, 2002), e inspirado en los trabajos de Schlager, Fusco y Schanck (1999) y del Grupo de Enseñanza y Aprendizaje de Illinois (1999).

En este sistema de categorías se trabajaron cinco dimensiones principales:

- Contenido teórico-práctico: reflexiones, aportaciones, información, etc., elementos propios del proceso de construcción de conocimiento.

- Tecnología: contenidos comunicativos sobre el uso de las herramientas tecnológicas.

- Socioemocional: formas utilizadas para el establecimiento de relaciones entre los participantes, cómo se presentan ante el grupo, cómo se apoyan entre sí, la existencia o no de emoticones, etc.

- Curso: aspectos organizativos, de funcionamiento y gestión de la actividad de aprendizaje que se desarrolla en la plataforma del proyecto.

- Gestión de la comunicación: contenidos codificados correspondientes a los dinamizadores de la herramienta de comunicación.

Hemos de tener en cuenta que cada foro incide en una temática diferente aun cuando el trasfondo sea el mismo: el análisis de la cultura existente y la promoción de la igualdad de oportunidades a través de la reflexión compartida. Bajo esta clave fueron analizados los foros a los que se refiere nuestro trabajo, ya que como señala De Pablos (2001: 152), "la construcción de la propia identidad cultural para cada sujeto supone una utilización consciente de la experiencia previa de dominio de la cultura propia en un escenario sociocultural concreto".

\section{Resultados del análisis de contenido de la comunicación online asincrónica en los foros e-Igualdad}

En la tabla 1, encontramos los resultados obtenidos tras la codificación de los contenidos comunicativos, siguiendo el sistema de categorías antes descrito, en 8 de los 18 foros activos al final en la web del proyecto. Los resultados se presentan organizados por dimensiones, categorías y sexo. Entre paréntesis indicamos los códigos correspondientes a los textos codificados en cada dimensión.

\begin{tabular}{|c|c|c|c|c|c|}
\hline \multirow{2}{*}{ Dimensión } & Categoría & \multicolumn{2}{|c|}{ Mujeres } & \multicolumn{3}{c|}{ Hombres } \\
\cline { 2 - 6 } & Valoración & $\mathrm{f}$ & $\%$ & $\mathrm{f}$ & $\%$ \\
\hline \multirow{2}{*}{$\begin{array}{c}\text { Contenido } \\
\text { teórico- práctico }\end{array}$} & Información. exploración de ideas & 42 & 85,7 & 7 & 14,3 \\
\cline { 2 - 6 } & Vonstrucción del conocimiento & 74 & 88,1 & 10 & 11,9 \\
\cline { 2 - 6 } $5=170$ & Actividades prácticas & 14 & 100 & 0 & 0 \\
\cline { 2 - 6 } $5,73 \%$
\end{tabular}




\begin{tabular}{|c|c|c|c|c|c|}
\hline \multirow{2}{*}{ Dimensión } & \multirow{2}{*}{ Categoría } & \multicolumn{2}{|c|}{ Mujeres } & \multicolumn{2}{|c|}{ Hombres } \\
\hline & & $f$ & $\%$ & $f$ & $\%$ \\
\hline & Total categoría & 152 & 89,4 & 18 & 10,6 \\
\hline Tecnología & Uso de la herramienta & 6 & 100 & 0 & 0 \\
\hline $\begin{array}{l}\Sigma=11 \\
3,6 \%\end{array}$ & Red o sistema & 5 & 100 & 0 & 0 \\
\hline & Total categoría & 11 & 100 & 0 & 0 \\
\hline \multirow{2}{*}{ Socioemocional } & Establecimiento de relaciones & 52 & 96,3 & 2 & 3,7 \\
\hline & Apoyo e integración en la tarea & 19 & 82,6 & 4 & 17,4 \\
\hline \multirow{2}{*}{$\begin{array}{c}\Sigma=101 \\
33,11 \%\end{array}$} & Información personal & 21 & 95,45 & 1 & 4,54 \\
\hline & Emoticones & 2 & 100 & 0 & 0 \\
\hline & Total categoría & 94 & 93,06 & 7 & 6,93 \\
\hline Curso & Programa & 0 & 0 & 1 & 100 \\
\hline$\sum=11$ & Orientación & 0 & 0 & 0 & 0 \\
\hline $3,6 \%$ & Organización & 9 & 81,8 & 1 & 18,18 \\
\hline & Total categoría & 9 & 90 & 2 & 10 \\
\hline $\begin{array}{l}\text { Gestión de la } \\
\text { comunicación }\end{array}$ & Contextualización & 5 & 83,3 & 1 & 16,6 \\
\hline \multirow{4}{*}{$\begin{array}{c}\Sigma=12 \\
3,93 \%\end{array}$} & \multirow[t]{2}{*}{ Didáctica } & 6 & 100 & - & 0 \\
\hline & & & & & \\
\hline & \multirow[t]{2}{*}{ Total categoría } & 11 & 91,6 & 1 & 8,3 \\
\hline & & 277 & 90,8 & 28 & 9,2 \\
\hline
\end{tabular}

Tabla 1. Frecuencias y porcentajes de uso de contenidos de las diferentes dimensiones y categorías, por sexo. Fuente: Elaboración propia

Atendiendo al sexo de los comunicantes, los participantes en los foros e-lgualdad, a pesar de ser éstos abiertos, fueron principalmente mujeres, aspecto lógico debido a la temática del proyecto y los contenidos ofertados en su web, espacio donde se insertaron los foros que aquí analizamos. Así, como se recoge en la tabla 1, el 90,8\% de los contenidos codificados pertenecen a mujeres. Si observamos ahora los gráficos 1 y 2 , el cómputo total de mensajes revela que ambos colectivos (hombres y mujeres) desarrollan un discurso con unos contenidos comunicativos similares. Sin embargo, hemos constatado que existen algunas diferencias. 


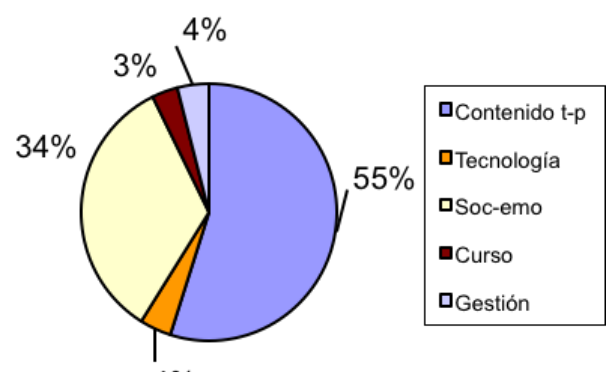

$4 \%$

Gráfico 1. Uso de códigos por dimensión. Mujeres (\%). Fuente: Elaboración propia

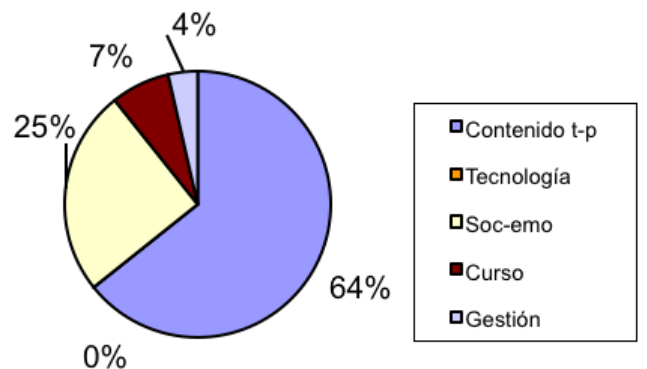

Gráfico 2. Uso de códigos por dimensión. Hombres (\%).Fuente: Elaboración propia

A la luz de los datos obtenidos, encontramos que los hombres hacen referencia al aspecto de "Contenido" (64\%) más que las mujeres (55\%). Los contenidos socioemocionales están, comparativamente, más presentes entre las mujeres $(34 \%)$ que entre los hombres (25\%). Esta circunstancia ya fue descrita por Wallace (2001, p.271). Según comenta esta autora, mientras que los hombres se orientan más hacia la práctica, las mujeres darían más importancia a la función socio-emocional, con el objeto de cohesionar el grupo y fomentar la cooperación. Además, mientras los primeros no se refieren en sus mensajes al aspecto de las TIC, las mujeres sí mencionan esta temática en sus mensajes.
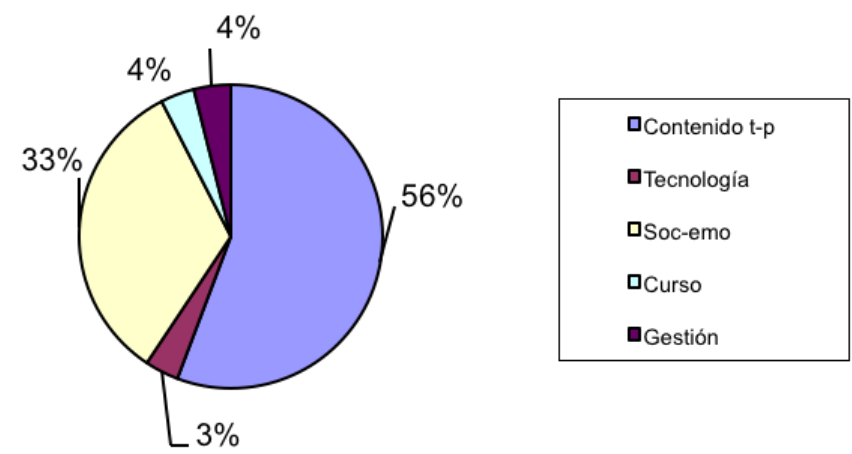

Gráfico 3. Uso de códigos por dimensión (\%). Fuente: Elaboración propia

Como observamos en el gráfico 3, la dimensión en la que aparece un mayor porcentaje de contenidos codificados de la comunicación mantenida en los foros es, con diferencia, la de "Contenido Teórico-Práctico" (55\%), seguida por la "Socioemocional" (33\%). Son, por tanto, los contenidos referidos a la construcción de conocimiento los que aparecen en el discurso con mayor frecuencia junto con los de identificación y 
reconocimiento social en el grupo participante en la actividad de comunicación y los que dan contenido principal a los foros analizados.

\subsection{Dimensión "Contenido Teórico-Práctico"}

Yendo en nuestro análisis dimensión por dimensión, encontramos que todas las categorías de la dimensión "Contenido Teórico-Práctico" (Gráfico 4) se han visto representadas en la comunicación mantenida entre los participantes en los foros e-Igualdad, siendo la de "Construcción del conocimiento" $(49,2 \%)$ junto con la de "Información" (28,8\%) las categorías más frecuentemente empleadas por los y las comunicantes. Esto refuerza la visión positiva del potencial educativo de los foros online como recurso para el aprendizaje, ya descrito en los estudios de Jeong (2003), Brito (2004) o Páez (2008), entre otros.

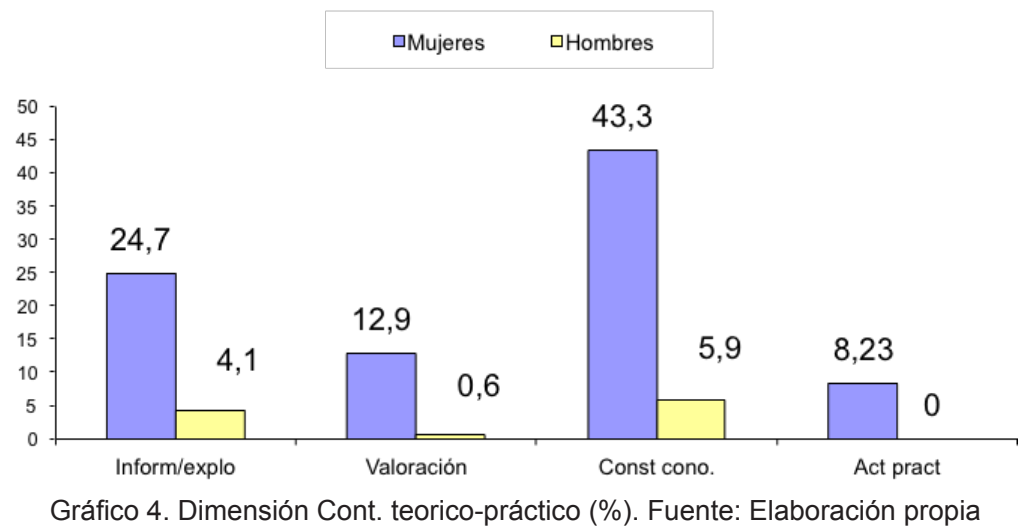

Si diferenciamos los resultados obtenidos por sexo, encontramos que los hombres participantes en los foros emiten mensajes, cuyos contenidos significan en el total de texto codificado el $10,8 \%$ de la dimensión, y que hacen alusión a aspectos propios de las categorías "Construcción del conocimiento" (5,9\%) y de "Información/ Exploración de Ideas" (4,1\%). Las mujeres por su parte, presentan el $89,13 \%$ de los contenidos codificados en el foro. En sus mensajes de todas y cada una de las categorías presentes en esta dimensión, fue nuevamente la de "Construcción del Conocimiento" la de mayor presencia (43,3\%), seguida por la de "Información" (24,7\%), "Actividades Prácticas" (8,23 \%) y "Valoración" (12,9\%).

La función principal que cumple el foro es la de ayudar a sus usuarios, hombres y mujeres, a que reflexionen y extraigan sus propias conclusiones (COE)

"Yo creo que las mujeres somos la causa de que el entorno socieconómico esté cambiando" (Mensaje 1, foro 7, 11/03/03, mujer).

extraídas a raíz de un debate basado en la argumentación (COA) de los participantes en el discurso,

"La sociedad sigue siendo machista, aunque lo camufle de intervenciones cada vez más políticamente correctas. Hablemos menos de igualdad y actuemos más para que esto realmente se produzca" (Mensaje 6, foro 2a, 20/02/03, hombre).

"Porque de lo que se trata, en definitiva, es de cambiar esos modelos profesionales que a las mujeres nos producen tanta inestabilidad en todas las esferas de nuestras vidas y que a los hombres no les provoca ningún tipo de cuestionamiento" (Mensaje 1, foro 6, 11/03/03, mujer). 
en el que se realizan aclaraciones, se aportan ideas, etc. (COR), tomando conciencia de las estrategias de mayor impacto para facilitar la transformación de la cultura, especialmente en la denominada cultura digital que se abre ante el colectivo de mujeres como un espacio de oportunidad en el que desarrollarse en igualdad.

"No solo el uso de Internet entre las mujeres si no también deberíamos aprender a guiarlas y motivarlas a que sean las propias mujeres las que demanden su inclusión en esta cultura digital de la que nosotras ya formamos parte" (Mensaje 4, foro $2 b, 12 / 03 / 03$, mujer).

Otro dato significativo lo encontramos en las otras dos categorías con mayor porcentaje de uso que son "Información y exploración de ideas" y "Valoración positiva o negativa sobre el tema". La primera significa que el intercambio comunicativo se hace basándose en preguntas y peticiones de información sobre el tema de discusión (CIP), unas veces denunciando el doble discurso existente en nuestra sociedad en relación al desarrollo de la igualdad de oportunidades

"esta tan necesaria si se cumpliera la ley de conciliación...si hubiera más guarderías públicas, si los horarios fueran flexibles... ¿tanto para las mujeres cómo para los hombres?" (Mensaje 6, foro 2d, 28/03/03, mujer).

y otras considerando la igualdad de oportunidad más allá de cuestiones ideológicas o segregadoras.

"Pero, ¿por qué estos planteamientos forman parte de discursos feministas? en torno a los temas de la conciliación? El patrimonio de la vida privada, ¿no es un bien a garantizar también por los hombres? ¿El cambio de modelos hemos de hacerlo hombres y mujeres en paralelo?" (Mensaje 1, foro 7, 11/03/03, mujer).

En otras ocasiones, la demanda de información es relativa a aspectos más prácticos como la mejora de la formación.

"Me gustaría saber todos los cursos que hay para poder hacerlo a través de Internet" (Mensaje 3, Foro 10, 31/05/04, mujer).

o sobre cómo realizar una determinada tarea (CAP) de las relacionadas con el uso de los recursos de la plataforma.

"¿Sabéis si desde la opción de "Estadísticas" veo sólo a mis alumnas? Decidme algo" (Mensaje 16, Foro 12, 20/02/04, mujer).

A veces, como medio para paliar la desorientación de la persona comunicante en las tareas formativas propuestas por el proyecto en su plataforma de formación virtual.

"A mí se me plantea una duda, a ver si me podéis ayudar. El itinerario de mis alumnas está formado (en algunos casos) por más de una actividad. En el gestor de itinerarios, la formadora ha calificado cada una de estas actividades formativas. Sin embargo, yo (como mentora) he tenido en cuenta una calificación global (he tenido en cuenta el itinerario completo)" (Mensaje 18, Foro 12, 24/02/04, mujer).

Las participantes mujeres hacen más preguntas que los hombres, tanto genéricas como centradas en las actividades, lo que está acorde con los hallazgos de Wallace (2001: 268). En cualquier caso, no debemos olvidar que el proyecto que analizamos en este trabajo tenía como principales beneficiarias y usuarias a mujeres de diversos perfiles (universitarias, mujeres en situación de desempleo, emprendedoras, empresarias, etc.). Es positivo entonces que hombres y mujeres se impliquen en los procesos de reflexión conjunta que analicen la naturaleza de la desigualdad de género, 
con el objeto de, por un lado, la sensibilización en torno a estas cuestiones y, por otro, la visibilización de los mecanismos que promueven y perpetúan la desigualdad en el desarrollo profesional y vital de las mujeres, en los que no han de ser cómplices hombres y mujeres. Se establece una dinámica de intercambio (CDI) cruzado de información a estos dos niveles: ideológico y práctico.

"Según me comenta Mariem, la persona de contacto en la Junta es Eloísa XXX" (Mensaje 26, Foro 12, 23/03/04, mujer).

donde se suceden los argumentos (COA) durante el debate, justificando el porqué de sus intervenciones. Ésta es la base de un diálogo razonado.

"Debéis de ver esta película, pues intenta ver una realidad de la juventud, en plano irónico que demuestra el sentir, de dos jóvenes en busca de su identidad en un mundo lleno de malos entendidos" (Mensaje 11, Foro 18, 12/08/04, mujer).

Se crea así un espacio de confianza y participación en el que aportar soluciones a problemas compartidos. Todo ello sirve para que las personas participantes extraigan sus propias conclusiones (COE) de los debates online y así lo manifiesten en sus mensajes, aportando posibles estrategias para paliar la desigualdad por cuestiones de género en la empresa.

"Yo soy participe de constituir empresas cooperativas autogestionarias de mujeres" (Mensaje 1, Foro 14, 19/12/03, mujer).

así como valoraciones sobre el tema de discusión, en ocasiones negativas (CVN) y en otras, positivas (CVP), sobre el programa formativo o del uso de los recursos del proyecto.

"Creo que este programa de Incubando Ideas es muy importante porque muchas mujeres la única alternativa que tienen es formando sus propias empresas" (Mensaje 2, Foro 14, 19/12/03, mujer).

"Hola a todas!! Me parece una propuesta genial este foro, el hecho que podamos seguir en contacto y sea un campo abierto a reflexiones, dudas, etc." (Mensaje 3, foro 3, 28/05/03, mujer).

\subsection{Dimensión "Tecnología"}

Como muestra el gráfico 5, la dimensión "Tecnología" sólo aparece representada en los mensajes emitidos por mujeres. Su contenido versó sobre temas relacionados con el uso de las herramientas tecnológicas. En más de una ocasión son mensajes enviados por formadoras o mentoras que comunican diversas vicisitudes encontradas en las herramientas de gestión insertadas en el portal.

"Hoy he comprobado que en "Estadísticas" (sabéis de qué os hablo) me aparecen alumnas a las que yo no he dado de alta (la verdad es que sólo son dos o tres). ¿Sabéis si desde la opción de "Estadísticas" veo sólo a mis alumnas?" (Mensaje 16, Foro 12, 20/02/04, mujer). 


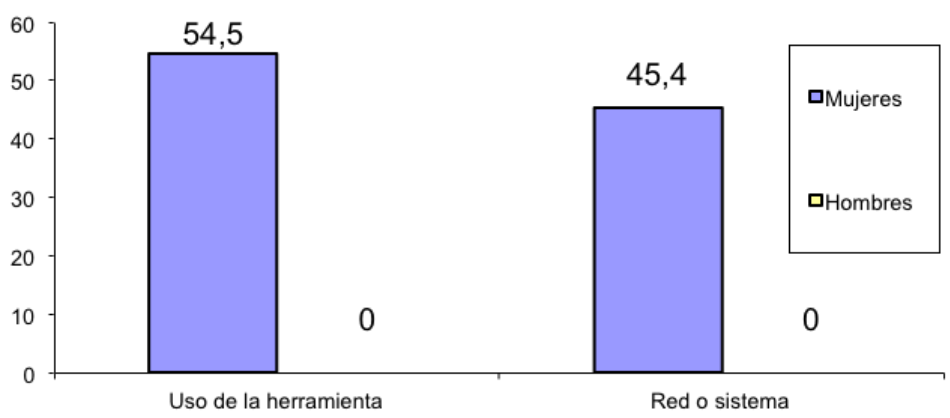

Gráfico 5. Foros. Dimensión Tecnología (\%). Fuente: Elaboración propia

Lo cual crea una dinámica entre las profesionales participantes en la gestión de los procesos de la plataforma e-Igualdad basada en compartir información, problemas vividos y soluciones técnicas, originadas a lo largo de la implementación de las distintas comunidades promovidas en el marco del proyecto. Se creó así un repositorio de conocimiento accesible a cualquier persona usuaria de los recursos de la web e-lgualdad.

En cualquier caso, la valoración que hacen las personas usuarias de las TIC en el foro es positiva, apreciando sus potencialidades, sobre todo en los aspectos relacionados con el uso de la red (TRP), en cuanto a las oportunidades que ofrece en términos de mejora de la empleabilidad a través de la formación, la aparición de nuevos yacimientos de empleo aún no saturados, etc.

"Las TIC, el teletrabajo, las redes nos dan nuevos instrumentos para construir nuestra 'empleabilidad'. Es un desafío y es una oportunidad. La flexibilidad es una arma valiosísima para las mujeres. El miedo al riesgo uno de nuestros frenos" (Mensaje 4, foro 2c, 28/02/03, mujer).

En cuanto a las plataformas empleadas para la formación en el portal hay usuarias que aprovechan el foro para valorarlas positivamente.

"Nuestra experiencia ha sido muy bonita y. En cuanto a la plataforma, es bastante intuitiva lo que hace que estés situada en todo momento durante el curso" (Mensaje 6, foro 3, 03/06/03, mujer).

Sin embargo, no falta algún que otro mensaje que aprovecha el foro para poner de manifiesto alguna dificultad encontrada en el uso de los distintos recursos TIC (THD) destacados en el portal e-Igualdad, normalmente relacionado más con el interface que con la parte técnica.

"Acabo de realizar el módulo disponible del curso y me parece muy bien, salvo un par de cuestiones para mejorar: 1.- la letra debería ampliarse porque hay que fijar mucho la vista y cansa y 2.- cuando el epígrafe se ve en color amarillo, molesta la vista ¿No podría cambiarse para que no fuera tan molesto? lo digo por evitar la "fatiga visual" tal y como recomiendan las normas sobre seguridad e higiene en el trabajo. Por último, cuando el módulo analiza los resultados de tus respuestas, los epígrafes primero y último son muy parecidos en cuanto al contenido y redacción. Apenas se distinguen. El resto me parece muy claro y muy bien formulado. Enhorabuena". (Mensaje 1, foro 6, 29/04/03, mujer). 


\subsection{Dimensión "Socio-Emocional"}

A simple vista, dos rasgos definen los contenidos codificados dentro de la Dimensión "Socio-emocional" (Gráfico 6). En primer lugar, a ella pertenecen contenidos comunicativos especialmente emitidos por mujeres (93\%). El segundo rasgo definitorio de esta dimensión es la importancia que tiene el "Establecimiento de relaciones" (SRS), en forma de saludos y despedidas, normalmente al inicio y al final de los mensajes, lo que hacen que esta categoría tenga la entidad que tiene en el discurso.

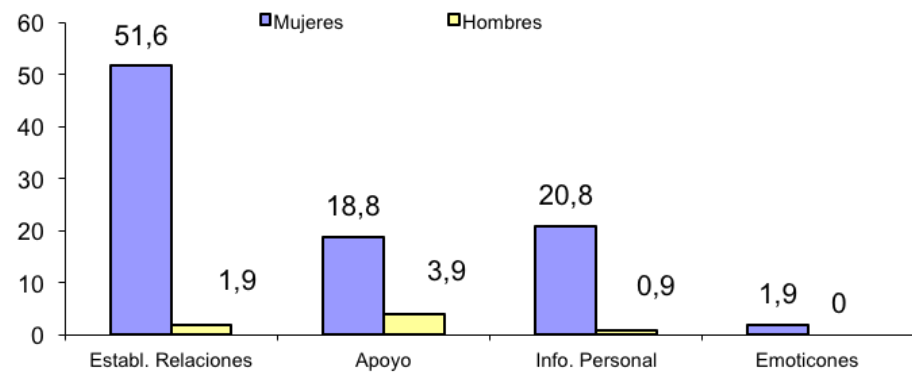

Gráfico 6. Foros. Dimensión Socio-emocional (\%). Fuente: Elaboración propia

De este modo, se emplean frecuentemente en los foros referidos a "Comunidades" (universitarias y tablón de actividades de las Formador@s y Mentor@s), quizás por ser estos dos espacios propicios para una comunicación más frecuente entre sus potenciales usuarias y sobre una temática específica. Estos saludos, ya son descritos por Herring (1996: 81) como convenciones epistolares propias de la comunicación a distancia. Las hemos encontrado en diferentes formatos:

\begin{tabular}{|c|l|}
\hline Forma genérica & "Hola chic@s!!" (Mensaje 11, Foro 12, 19/01/04, mujer) \\
\hline $\begin{array}{c}\text { Dirigidos a una determinada } \\
\text { persona }\end{array}$ & "Hola Mª Luisa!!" (Mensaje 23, Foro 12, 22/03/04, mujer) \\
\hline $\begin{array}{c}\text { Como antesala de una } \\
\text { presentación }\end{array}$ & $\begin{array}{c}\text { "Hola, soy Pamela" (Mensaje 18, Foro 9, 19/08/04, mujer) } \\
\text { "Hola a tod@s, soy Cristina (AES)" (Mensaje 09, Foro 12, }\end{array}$ \\
\hline Más o menos afectuosos & "Un besote para todas" (Mensaje 20, Foro 9, 19/08/04, mujer) \\
\hline
\end{tabular}

Tabla 2. Formatos de saludos. Fuente: Elaboración propia

También en los foros hay lugar para las bromas (SRB) entre los participantes, pese a ser un espacio asincrónico.

“¿Cómo voy a terminar?, esto es infinito. Sueño con esto, tengo pesadillas" (Mensaje 24, Foro 12, 22/03/04, mujer).

Lejos de ser un espacio impersonal, en el foro sus usuarios reconocen a quienes son sus compañeros comunicantes (SRR) a través de su participación.

"Ahora veo que tu entras con los códigos de María y yo te dije el otro día María, bueno, lo siento, ya lo sé, pues nada Cristina" (Mensaje 19, Foro 12, 04/03/04, mujer).

La otra forma de comunicación que cobra gran valor en esta dimensión es la de "Apoyo e integración a la tarea", que supone el 18,8\% de la comunicación de esta dimensión en el caso de las mujeres y el 3,9\% en el caso de los hombres. Esta categoría 
aparece principalmente en forma de incitaciones a la participación (SAP) al resto de los y las compañeras. Fundamentalmente, estos contenidos aparecen concentrados en el foro Tablón de actividades, correspondiente a la Comunidad de Formador@s y Mentor@s, los que nos permite pensar que la motivación entre los comunicantes es fundamental para mantener el foro vivo.

"estoy evaluando todo lo que se acaba de terminar uff que trabajera eh?? ¿cómo lo lleváis ?? Y el portal os va bien???" (Mensaje 8, Foro 12, 17/12/03, mujer).

"Si estáis interesadas en participar en el Taller y en asistir a esta sesión haced clic en "Participa en el taller» y solicitad vuestra inscripción en el taller" (Mensaje 1, Foro 15, 04/03/04, hombre).

No es raro encontrar esta vertiente de socio afectiva de apoyo entre las mujeres en los foros (Wallace, 2001: 271) que lo utilizan frecuentemente para animarse entre sí (SAP) a participar en actividades online o presenciales del proyecto,

"Sinceramente considero que este espacio nos va a resultar de gran utilidad. Os animo a todas a que participéis en el mismo y a que sigamos manteniendo el contacto que en el curso que hemos realizado hemos establecido" (Mensaje 1, foro 3, 27/05/03, mujer).

"Hola chicas. Pues sí que tiene que ser interesante. Voy a ser todo lo posible por asistir" (Mensaje 9, foro 3, 03/06/03, mujer).

o para acoger y apoyar a otras compañeras (SAA), de manera que pueden entender mejor el lenguaje emocional implícito de las aportaciones realizadas por los comunicantes (Hall, 1984: 198).

"Hola querida amiga! Entiendo cómo te sientes. Yo tengo la misma visión que tienes tú. Me considero una persona justa y el mundo laboral está lleno de injusticias.

Pero hay que mirar el lado bueno" (Mensaje 8, foro 7, 26/03/03, mujer).

Otro aspecto de interés es el que se refiere a las referencias a aspectos personales, donde las mujeres se llevan la palma nuevamente, revelándose nuevamente situaciones que caracterizan el riesgo de padecer desigualdad: la auto exigencia, que se trasluce al comunicar aspectos personales de carácter emocional (SIE),

"Estoy muy contenta aunque como soy una agonía, sigo haciendo cursos, buscando otros trabajos" (Mensaje 18, Foro 9, 19/08/04, mujer).

"Cuando vi las horas me sentí removida y hasta incómoda" (Mensaje 6, foro 9, 24/04/03, mujer).

Sus miedos, ligados al ámbito de lo laboral (SIL),

"Me refiero que como mujer que soy quiero desarrollarme tanto personal como profesionalmente pero parece que el entorno entorpece esta filosofía. Si quieres desarrollarte profesionalmente puedes cargarte la vida personal y viceversa" (Mensaje 1, foro $7,11 / 03 / 03$, mujer).

"Sabes que estoy currando?? en el Ayuntamiento de Estepa, en la Delegación de Juventud" (Mensaje 18, Foro 9, 19/08/04, mujer).

o sus complejos al referirse a experiencias de aprendizaje vividas (SIA).

"Tú sabes, yo soy además poco inteligente y no tengo habilidad para el estudio, pero a mí me hubiera gustado estudiar mucho para ser catedrática, pero claro, yo no servía para eso" (Mensaje 15, Foro 17, 17/12/03, mujer). 
También dentro de esta dimensión se incluye el uso de emoticonos, dato acorde con las investigaciones de Witmer y Katzman (1997). Fueron utilizados en muy pocas ocasiones y sólo por mujeres, en nuestro caso la coordinadora de la Comunidad de Formador@s y Mentor@s.

\subsection{Dimensión "Curso"}

Otra de las dimensiones contempladas en este análisis fue la de "Curso" (Gráfico 7) dentro de la cual aparecen todos aquellos contenidos comunicativos que giran en torno a los procesos de formación de las usuarias desarrollado a raíz del proyecto. Sin embargo, ésta no fue una dimensión que aparece significativamente reflejada en los foros e-Igualdad (3,6\% del total de contenidos codificados). Esta circunstancia es comprensible por cuanto los foros no fueron inicialmente pensados en relación con la formación sino con los contenidos desarrollados en el proyecto. La categoría con mayor presencia dentro de esta dimensión fue "Organización" (Gráfico 7) a la que corresponden el 90,9\% de los contenidos de la dimensión. Éstas aparecen en el Tablón de actividades de las Formador@s y Mentor@s.

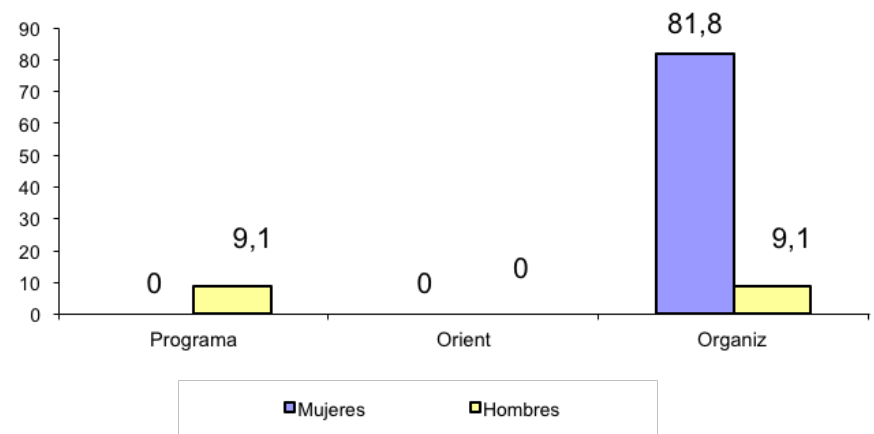

Gráfico 7. Dimensión Curso (\%). Fuente: Elaboración propia

El uso de este tipo de comunicación ha pasado de estar protagonizada por las universitarias, usuarias de la formación en el primer año del proyecto (Acción 2), a través de la cual mostraban principalmente su preocupación por el tema de la certificación de los cursos, a las formadoras que comparten esta preocupación pero desde el punto de vista de la Organización (VGO), es decir, de los y las responsables de la formación online del proyecto en varios sentidos. En lo relativo a la implementación de la formación, bien como vía de expresión de la sobrecarga propia del gran trabajo que les supone a formadoras y mentoras la implementación de los cursos de formación,

"Respecto al trabajo un poco a tope, todavía estoy creando ediciones tutorizadas y a la búsqueda y captura de usuarias de autouso" (Mensaje 28, foro 12, 30/03/04, mujer).

o relacionado con la gestión, concretamente en lo relacionado con las tareas burocráticas, centrándose casi exclusivamente en el cumplimiento de los requisitos solicitados por la Administración para la certificación de los cursos online:

"Si es cierto yo no dejo de pensar que es todo lo que se me viene encima con la justificación, ¿tú has empezado ya? ¿Alguien sabe si tarda mucho la Junta en mandar o darte contestación a los certificados?" (Mensaje 25, foro 12, 25/03/04, mujer).

o con las tareas propias de la planificación como las alusiones al programa de los cursos o actividades propuestas por el proyecto Andalucía en e-Igualdad, 
“El taller tendrá una duración de 6 semanas, con una carga de trabajo máxima de 50 horas en total y contará con dos sesiones presenciales. Precisamente el día 10 de marzo dará comienzo la $3^{a}$ edición del taller Transformando en e-igualdad con una sesión presencial que se celebrará en Sevilla, de 16h30 a 19h30" (Mensaje 1, Foro 15, 04/03/04, hombre).

\subsection{Dimensión "Gestión de la Comunicación"}

La última dimensión que nos resta por comentar es la de "Gestión de la Comunicación" (Gráfico 8), que ha supuesto un 3,9\% de los contenidos comunicativos recogidos en los foros del portal. Dentro de ella, encontramos representadas las dos categorías de la dimensión: Contextualización y Didáctica, principalmente por intervenciones realizadas por mujeres, a las que corresponde el 91,6\% de los contenidos. Aparecen la mayoría de ellos en el foro Tablón de Actividades de Formador@s y Mentor@s.

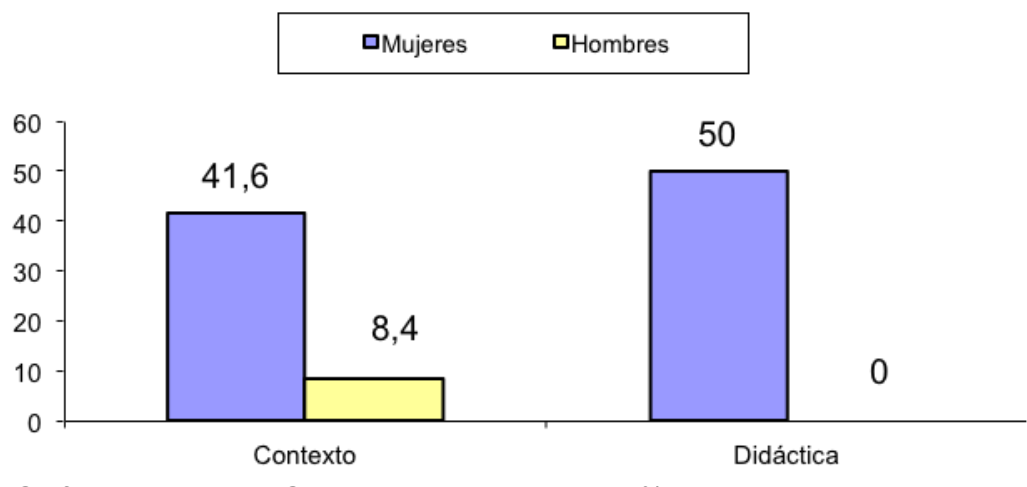

Gráfico 8. Dimensión Gestión de la comunicación (\%). Fuente: Elaboración propia

La función de Contextualización se refiere principalmente al Reconocimiento (GXR) de las usuarias del foro. En unos casos como herramienta utilizada para la convocatoria de reuniones presenciales de la comunidad de Formador@s y Mentr@s,

“Hola a tod@s yo si estaré, a ver si os animais!!!” (Mensaje 14, foro 12, 04/02/04, mujer).

para que los y las formadoras o mentoras se presenten ante potenciales usuarias de los foros

"Para cualquier duda siempre podréis acudir a mí que seré el tutor durante esta edición. Mi nombre es Manuel XXX y mi correo mXXX@e-igualdad.org" (Mensaje 19, foro 12, 04/03/04, hombre).

o como medio en el que definir formas de participación (GXN) en las distintas actividades programadas dentro del proyecto

"sería cosa de preguntarle a Ana XXX, ¿oye? el e-mail de Ana es que dice que está ya casi el documento para la certificación ¿no? Yo eso no lo haré hasta finales de Abril - Mayo. Cuando ya terminen todas las usuarias" (Mensaje 1, foro 15, 04/03/04, mujer).

Respecto a la función Didáctica, se refleja únicamente en el análisis de la marcha de los diferentes cursos ofertados (GDM) en el contexto del proyecto. 
“¿qué tal vuestras usuarias en estas fechas? Yo no tengo ninguna edición puesto que la gente ahora en estas fechas nada de nada, eso sí, estoy evaluando todo lo que se acaba de terminar" (Mensaje 8, foro 12, 17/12/03, mujer).

\section{Conclusiones}

Como hemos podido observar a lo largo del presente trabajo, los foros e-Igualdad han contribuido a la expresión escrita de muchos de los referentes culturales que han construido la identidad de las personas participantes en los debates virtuales. Muchos de ellos ligados a patrones no favorecedores de la igualdad entre hombres y mujeres. El uso de los foros online se ha revelado como una estrategia positiva para reflexionar sobre el papel que juega hoy día la mujer en el desarrollo de la Sociedad de la Información y el Conocimiento, la búsqueda activa de alternativas a la desigualdad, como espacios en los que pensar sobre ella y analizar su impacto en las emociones y desarrollo vital de las mujeres o como lugares en los que propiciar nuevos modelos de rol positivos.

Asimismo, hemos podido confirmar el potencial educativo del uso de herramientas TIC asincrónicas, hecho ya descrito en otros estudios. La comunicación establecida en los foros aporta un espacio adecuado para la construcción colaborativa de conocimiento entre los distintos participantes en el discurso. Este hecho es reconocido por las mismas usuarias del foro, considerándolo un medio idóneo para la expresión de principios e ideas que traslucen el cambio de valoración de las mujeres en el contexto cultural actual y analizan críticamente su consideración a lo largo de la historia reciente de nuestro país. Como nos recuerda Espinosa (2011), construimos nuestra realidad a través de nuestras interpretaciones, por lo que la dinámica establecida en los foros, de información y aportación de ideas previa a la extracción de conclusiones, ha sido un aspecto muy positivo en el desarrollo de una visión crítica del papel de la mujer hoy.

La dinámica establecida de preguntas y respuestas, como base de la argumentación, tanto ideológica como sobre la práctica, propia del método socrático de enseñanza, suele ser habitual en el trabajo de los foros asincrónicos e-Igualdad, siendo las mujeres sus principales protagonistas. Así, la oportunidad de compartir experiencias y conocimiento ha sido fructífera y valorada positivamente por sus protagonistas. Se posibilitó, de este modo, la puesta en valor de la experiencia de las participantes, su análisis de las situaciones de desigualdad a las que se enfrentan o se han enfrentado, las posibles alternativas que facilitarían la mejora de su situación, etc.

En definitiva, el proyecto Andalucía en e-lgualdad, a través de sus recursos online, ha posibilitado la reflexión sobre la igualdad de oportunidades desde una visión crítica, ya que el primer paso hacia el cambio cultural y la innovación social es la concienciación, la visibilización tanto del problema como de las soluciones y el reconocimiento del capital humano de una sociedad, del que forman parte, necesariamente, las mujeres. 


\section{Bibliografía}

Aguirre, A. (2004). La cultura de las organizaciones. Barcelona: Ariel.

Allwright, R. (1984). Why don't learners learn what teachers teach? -The interaction hypothesis. En Singleton, D. y Little, D. (eds.), Language learning in formal and informal contexts. Dublín: IRAAL.

Brito, V. (2004). El foro electrónico: una herramienta tecnológica para facilitar el aprendizaje colaborativo. Edutec. Revista Electrónica de Tecnología Educativa, $\mathrm{n}^{\circ} 17$. Recuperado de http://edutec.rediris.es/Revelec2/revelec17/brito_16a.pdf.

Buraphadeja, V. y Dawson, K. (2008). Content Analysis in Computer-Mediated Communication: Analyzing Models for Assessing Critical Thinking Through the Lens of Social Constructivism. American Journal of Distance Education, (22) 3, 130-145. DOI: http:// dx.doi.org/10.1080/08923640802224568.

Castells, M. (1998). La era de la información. Economía, sociedad y cultura. Vol. 2. El poder de la Identidad. Madrid: Alianza Editorial.

Cebrián, J. L. (1998). La red. Madrid: Santillana.

Chan, M. E. (2005). Competencias mediacionales para la educación en línea. Revista Electrónica de Investigación Educativa, 7 (2). Recuperado de http://redie.uabc.mx/ vol7no2/contenido-chan.html.

Conrad, R. M. y Donaldson, J. A. (2004). Engaging the online learner. Activities and resources for creative instruction. San Francisco, California: Jossey-Bass.

Cook-Shater (2000). Typology and Texture: An analysis of How Pre and In-service teachers learn together throung weaving dialogue, conversations, narrative and talk. En Clark, C.M. (ed.), Learning by talking: Conversations and Storelling in Teacher Education and Professional Development.

Crook, C. (2001). The social character of knowing and learning: implications of cultural psychology for educational technology. Technology, Pedagogy and Education, 10 (1), 19-36.

Declaración de Principios de Ginebra (2004). Cumbre Mundial sobre Sociedad de la Información "Construir la Sociedad de la Información: Un desafío mundial para el nuevo milenio" (Ginebra 2003-Túnez, 2005). Documento WSIS-03/GENEVA/DOC/0004. Recuperado de http://www.itu.int/wsis.

De la Mata, M.; Cala, M. J.; Cubero, M.; Cubero, R. y Santamaría, A. (2009). El aprendizaje en el aula desde la Psicología Histórico-Cultural: Interacción social, discurso y tecnologías de la comunicación. En De Pablos Pons, J. (coord.), Tecnología educativa. La formación del profesorado en la era de Internet. Málaga: Aljibe.

De Pablos, J. (2001). Los estudios culturales y la comunicación. En Area, M. (coord.). Educar en la Sociedad de la Información. Bilbao: Desclée de Brouwer.

De Pablos, J. (2004). De Velázquez al Hipertexto: algunas implicaciones socioculturales. Aula Abierta, $\mathrm{n}^{\circ}$ 84, 103-116.

De Pablos, J. (2005). La Pintura y su Influencia en el Cine. Una Aproximación Pedagógica a la Obra de Edward Hopper. Enseñanza. Anuario Interuniversitario de Didáctica, $\mathrm{n}^{\circ}$ $23,103-114$. 
De Pablos, J. (2006). El Cine y la Pintura: una Relación Pedagógica. Una Aproximación a Víctor Erice y Edward Hopper. Icono 14. Revista de Comunicación y Nuevas Tecnologías, 4 (1), 1-15.

De Pablos, J. (2009). Tecnología educativa. La formación del profesorado en la era de Internet. Málaga: Aljibe.

Espinosa, A. (2011). Redes horizontales y sostenibilidad de sistemas complejos. Anduli. Revista Andaluza de Ciencias Sociales, n 10, 111-119.

Estebaranz, A. (2005). Educación familiar y valores: Hacia la igualdad de género en una sociedad democrática. Ponencia presentada en el IV Congreso Mundial de Educación Infantil y Formación de Educadores. En Ética, Estética y Estrategias Didácticas en Educación Infantil. Málaga: Grupo de Investigación "Educación Infantil y Formación de Educadores", v. 2.

Estebaranz, A. (2007). Estrategias didácticas para la innovación educativa. En Medina, A.; Muñoz, J.; Egido, I.; Estebaranz, A. y Rodríguez, A., Perspectivas didácticas para el Siglo de la Educación. Madrid: Fundación Fernando Rielo.

Estebaranz, A.; Mingorance, P. y Ballesteros, M. A. (2001). Comunicación online para la formación: Un sistema de Análisis. En Tecnologías de la Información en el nivel de formación superior avanzada. Salamanca: AUIP.

Feliu, V. (1999). Dinámica y evaluación de las listas. Recuperado de http://www.xtec. es/ vfeliu/ dina1.htm.

Fonseca, M. C. (2009). Edublogs: Blog's para educar. En Castaño, C. (coord.), Web 2.0. El uso de la web en la Sociedad del Conocimiento. Investigación e implicaciones educativas. Caracas: Universidad Metropolitana.

García-Madrigal, F. y Vicén, C. (1994). Fundamentos de comunicación humana. Zaragoza: Mira Editores.

Gisbert, M. (2000). El Siglo XXI, hacia la sociedad del conocimiento. En Cabero, J.; Salinas, J. y Martínez, F. (coord.), Medios audiovisuales y nuevas tecnologías para la formación en el siglo XXI (277-288). Murcia: DM.

Gómez, C. (2001). Mujeres y trabajo: principales ejes de análisis. Papers: Revista de Sociología, $\mathrm{n}^{\circ}$ 63-64, 123-140.

Grupo de enseñanza y aprendizaje de Illinois (1999). Report of the University of Illinois. Teaching at an Internet Distance Seminar. Recuperado de http://www.upaa.uillinois. edu/tid/report/.

Hall, J.A. (1984). No verbal sex differences: Communication accuracy and expressive style. Baltimore: Johns Hopkins University Press.

Hara, N., Bonk, C., y Angeli, C. (2000). Content Analysis of online discussion in anapplied educational psychology course. Instructional Science, $\mathrm{n}^{\circ} 28,115-152$. DOI: http:// dx.doi.org/10.1023/A:1003764722829.

Hawkes, M. (2006). Linguistic Discourse Variables as Indicators of Reflective Online Interaction. American Journal of Distance Education, 20 (4), 231-244. DOI: http://dx.doi. org/10.1207/s15389286ajde2004_4.

Herring, S.C. (1996). Two variants of an electronic messege schema. En Herring, S.C. (comp.), Computer-mediated communication: Lingüistic social and cross cultural perspectives. Amsterdam/Filadelfia: John Benjamin Publishing Company. 
Hoyos, G. y Martínez, M. (2004). ¿Qué significa educar en valores hoy? Barcelona: Octaedro.

Inoue, V. (2008). Tecnologías para e-learning: Introducción y escenario actual. Learning Review, $\mathrm{n}^{\circ} 4$, octubre-diciembre, 16-17.

Jeong, A.C. (2003). Sequential analysis of group interaction and critical thinking in online threaded discussions. American Journal of Distance Education, 17 (1), 25-43. DOI: http://dx.doi.org/10.1207/S15389286AJDE1701_3.

Lara, T. (2005). Blogs para educar. Usos de los blogs en una pedagogía constructivista. Telos: Cuadernos de comunicación e innovación, nº 65, 86-93.

Martín, P. (2007). El Foro como sistema de comunicación e interacción. Revista Complutense de Educación, 18(1), 95-112.

Mas, O. et al. (2006). Las comunidades virtuales de aprendizaje. Nuevas fórmulas, viejos retos en los procesos educativos. En Méndez-Vilas, A.; Solano, J.A. y Mesa, J. (eds.), Current Developments in Technology-Assisted Education. Badajoz: FORMATEX.

Michaelson, G. y Pohl, M. (2001). Gender in email-based co-operative problem solving. En Green, E. y Adam, A. (eds.), Virtual gender. Technology, consumption and identity. London: Routledge.

Mingorance, P. y Estebaranz, A. (2009). Escuela y comunidad. El proceso de aprender a transformar la sociedad. Revista de orientación educacional, nº 43, 101-125.

Molina, J. F.; López, M.D.; Pereira, J.; Pertusa, E. y Tarí, J. J. (2012). Métodos híbridos de investigación y dirección de empresas. Ventajas e implicaciones. Cuadernos de economía y dirección de la empresa, 15 (2), 55-62.

Nagel, K. (1994). The natural life cycle of mailing lists. Recuperado de http://catalog.com/ vivian/lifecycle.

Ornelas, D. (2007). El uso del Foro de Discusión Virtual en la enseñanza. Revista lberoamericana de Educación, $\mathrm{n}^{\circ}$ 44. Recuperado de http://www.rieoei.org/expe/1900 Ornelas.pdf.

Ortega, J. A. (1999). Comunicación visual y tecnología educativa. Perspectivas curriculares y organizativas de las Nuevas Tecnologías aplicadas a la Educación. Granada: Grupo Editorial Universitario.

Ortega, J. A. (2004). Un profesorado para la Sociedad del Conocimiento: Construyendo un currículo intercultural desde la cibernética emergente. Comunicación y Pedagogía, no $195,32-37$.

Ortega, J. A. y Chacón, A. (2007). Nuevas tecnologías para la Educación en la Era Digital. Madrid: Pirámide.

Páez, H. G. (2008). Pensamiento crítico en el foro electrónico de discusión. Investigación y posgrado, 23(2), 145-174.

Reyes, M. M. y Toledo, P. (2008). Educación familiar. Sevilla: Mergablum.

Sánchez, A. A. (2001). Internet y la Sociedad Europea de la Información: implicaciones para los ciudadanos. Sevilla: Secretariado de Publicaciones de la Universidad de Sevilla.

Sevillano, M. L. (2007). Nuevas tecnologías, nuevos medios y didáctica buscan convergencias formativas. Bordón, 52(2-3), 451-473. 
Sevillano, M. L. (2008). Tecnologías y medios de comunicación en la investigación desde la perspectiva de género. En Jiménez C. y Pérez Serrano (coords.), Educación y género el conocimiento invisible. Madrid: UNED.

Sevillano, M. L. (2009). Posibilidades formativas mediante nuevos escenarios virtuales. Educatio Siglo XXI, 27 (2), 71-94.

Sierra, B. (2000). La comunicación como simulación: un nuevo estilo de una nueva era. En Pérez, R. (coord.). Redes, multimedia y diseños virtuales. Oviedo: Servicio de Publicaciones de la Universidad de Oviedo.

Schlager, M. S.; Fusco, J. y Schank, P. (1999). Evolution of an On-line Education Community of Practice. En Renninger, K. A. y Shumar, W. (coords.). Building virtual communities: Learning and change in cyberspace. Nueva York: Cambridge University Press.

Tesouro, M. y Puiggalí, J. (2006). Las comunidades virtuales y de conocimiento en el ámbito educativo. Píxel-Bit. Revista de Medios y Educación, n² 28, 99-110.

Tirado, R.; Boza, A. y Guzmán, M. D. (2008). Efectos de las interacciones en la creación de comunidades virtuales de prácticas. RED. Revista de Educación a Distancia, $\mathrm{n}^{\circ} 21$, diciembre. Recuperado de http://www.um.es/ead/red/21.

Urra, P. A. (2007). El blog y los foros de discusión: diferencias y complemento. Acimed: Revista Cubana de los Profesionales de la Información y la Comunicación en Salud, (16) 1. Recuperado de http://bvs.sld.cu/revistas/aci/vol16_1_07/aci11707.htm.

Varis, T. (2003). New literacies and e-learning competences. Recuperado de http://www. elearningeuropa.info/es/node/2328.

Wallace, P. (2001). La psicología Internet. Barcelona, Paidós.

Witmer, D. F. y Katzman (1997). On-line smiles: Does gender make a difference in the use of graphic accents? Journal of Computer-Mediated Communication, 2 (4). Recuperado de http://jcmc.indiana.edu/ vol2/issue4/witmer1.html.

Youngs, G. (2001). Theoretical reflections on networking in practica. The case of women on the net. En Green, E. y Adam, A. (eds.). Virtual gender. Technology, consumption and identity. London: Routledge. 